\title{
Metabolic Syndrome and Coronary Artery Disease in Indians Younger Than 40 Years
}

\author{
Amitesh Aggarwal ${ }^{\mathrm{a}, \mathrm{b}}$, Sourabh Aggarwala, Vishal Sharma ${ }^{\mathrm{a}}$
}

\begin{abstract}
Background: Indians have highest risk rates of coronary artery disease (CAD) amongst all ethnic groups. The impact of metabolic syndrome (MS) has not been studied, especially in the young. This study analyzes the prevalence of metabolic syndrome and its various components in young Indians with CAD.
\end{abstract}

Methods: The study was conducted at a tertiary teaching hospital in New Delhi. A retrospective case record analysis of 403 patients presenting acutely with young (age $\leq 40$ year) CAD during the period Jan 2005 - Dec 2009 was done. The criterion advocated by International Diabetes Federation (IDF) consensus 2005 was used for diagnosing patients with MS. The data was then used to find the prevalence of derangement of various metabolic parameters in all patients and in those with MS. Statistical analysis was done using SPSS v.17.

Results: Patients (246) were selected for study. Metabolic syndrome was present in 66 patients $(26.8 \%)$. In patients with young CAD low HDL was found in 171 (69.5\%), raised triglycerides 103 patients $(41.9 \%)$, hypertension in 55 patients $(22.4 \%)$ and impaired fasting glucose /diabetes mellitus in 54 patients $(21.9 \%) ; 187$ (75.6 $\%$ ) patients had history of smoking; 64 patients $(26.0 \%)$ had a family history of young cardiovascular disorders; 13 females out of 28

Manuscript accepted for publication February 9, 2012

${ }^{\mathrm{a}}$ Department of Medicine, University College of Medical Sciences (University of Delhi) and GTB Hospital, Delhi 110095, India

${ }^{\mathrm{b}}$ Corresponding author: Amitesh Aggarwal.

Email: dramitesh@gmail.com

doi:10.4021/jem81e
(46.4\%) and 53 males out of 218 (24.3\%) met criteria for diagnosis of MS. Prevalence of MS in females was significantly more than males $(\mathrm{P}<0.02)$. Among 66 patients diagnosed with MS, low HDL was seen in 52 patients $(78.8 \%)$, raised triglycerides in 49 patients (74.2\%), hypertension in 36 patients $(54.5 \%)$ and dysglycemia in 35 patients $(53.0 \%) ; 4$ patients $(71.2 \%)$ had history of smoking. A positive family history of premature cardiovascular disorders was present in 26 patients (39.4\%). Among patients with young CAD, prevalence of smoking was more in males compared to female patients $(\mathrm{P}<0.005)$ whereas hypertension and obesity in were noted more often in female patients $(\mathrm{P}<0.005)$.

Conclusions: This study confirms a high prevalence of MS in patients with young CAD. This study also underlies the importance of smoking and dyslipidemia as primary targets for effective prevention of CAD and MS in young Indians.

Keywords: Young; Coronary artery disease; Metabolic syndrome; Indian

\section{Introduction}

Coronary artery disease (CAD) is the leading cause of morbidity and mortality in both developing and developed countries. Approximately, one-sixth of world's population lives in India and CAD remains the highest cause of mortality in India [1]. Indians have the highest mortality rates amongst all ethnic groups studied so far. It is a well established fact that the South Asian population especially Indian sub-continent has higher risk and wider prevalence of CAD as compared to rest of ethnic groups $[2,3]$. Deaths related to CAD occur 5 to 10 years earlier in Indian sub-continent than in Western countries [4].

Metabolic syndrome (MS), a constellation and complex web of metabolic features, is very common among population of Indian sub-continent [5, 6]. The prevalence of MS has been rising alarmingly in recent times due to decreased physical activity and abnormal dietary patterns [7]. Patients with MS have a $30-40 \%$ probability of developing CAD within 20 years depending upon number of components present [8]. Various studies have highlighted the predictability of CAD 
Table 1. Coronary Risk Factor Profile of Patients With Young CAD

\begin{tabular}{|c|c|c|c|c|}
\hline & $\begin{array}{c}\text { Total } \\
(n=246)\end{array}$ & $\begin{array}{c}\text { Male } \\
(n=218)\end{array}$ & $\begin{array}{l}\text { Female } \\
(n=28)\end{array}$ & P value \\
\hline Age in years $($ mean $\pm \mathrm{SD})$ & $36.3 \pm 4.1$ & $36.2 \pm 4.1$ & $37.5 \pm 3.5$ & NS \\
\hline Metabolic syndrome & $66(26.8 \%)$ & $53(24.3 \%)$ & $13(46.4 \%)$ & $<0.025$ \\
\hline Smoking & $187(76.0 \%)$ & $177(81.2 \%)$ & $10(35.7 \%)$ & $<0.001$ \\
\hline Family History & $64(26.0 \%)$ & $54(24.8 \%)$ & $10(35.7 \%)$ & NS \\
\hline $\begin{array}{l}\text { Fasting plasma glucose } \geq 100 \text { or } \\
\text { previously diagnosed DM }\end{array}$ & $54(21.95 \%)$ & $45(20.6 \%)$ & $9(32.1 \%)$ & NS \\
\hline Hypertension & $55(22.4 \%)$ & $42(19.3 \%)$ & $13(46.4 \%)$ & $<0.005$ \\
\hline $\begin{array}{l}\text { Reduced HDL cholesterol }(<40 \\
\mathrm{mg} / \mathrm{dL} \text { in males and }<50 \mathrm{mg} / \mathrm{dL} \text { in } \\
\text { females })\end{array}$ & $171(69.5 \%)$ & $148(67.9 \%)$ & $23(82.1 \%)$ & NS \\
\hline $\begin{array}{l}\text { Increased Triglycerides ( } \geq 150 \mathrm{mg} / \\
\mathrm{dL} \text { ) }\end{array}$ & $103(41.9 \%)$ & $92(42.2 \%)$ & $11(39.3 \%)$ & NS \\
\hline $\begin{array}{l}\text { Obesity ( } \geq 80 \mathrm{~cm} \text { in females and } \geq \\
90 \mathrm{~cm} \text { in males) }\end{array}$ & $122(49.6 \%)$ & $100(45.9 \%)$ & $22(78.6 \%)$ & $<0.005$ \\
\hline Waist circumference $(\mathrm{cm})$ & $87.1 \pm 10.5$ & $87.2 \pm 10.6$ & $86.4 \pm 10.1$ & NS \\
\hline Total cholesterol (mg/dL) & $171 \pm 51.8$ & $172.2 \pm 53.9$ & $165.3 \pm 31.1$ & NS \\
\hline LDL cholesterol (mg/dL) & $102.5 \pm 45.8$ & $103.6 \pm 47.4$ & $93.5 \pm 30.6$ & NS \\
\hline HDL cholesterol (mg/dL) & $36.7 \pm 9.3$ & $36.4 \pm 9.2$ & $38.5 \pm 10.5$ & NS \\
\hline Triglycerides (mg/dL) & $156 \pm 85.7$ & $157.2 \pm 88.2$ & $150 \pm 63.7$ & NS \\
\hline
\end{tabular}

NS- not significant.

and presence of unstable lipid rich plaques on basis of presence of MS [9-11]. However, clinical studies analyzing the impact of MS on CAD in young patients are very limited [12]. The association and impact of MS on young $(\leq 40$ years) patients with CAD has not been studied extensively in Indian setup. Considering the ever increasing prevalence of MS and young CAD in Indian subcontinent, this study was aimed at studying the prevalence of metabolic syndrome and its various components in patients with young CAD and observes their association with CAD.

\section{Methods}

The present study was conducted at our 1200 bedded teaching Hospital, a tertiary health-care center in the city of Delhi.
A retrospective case record analysis of 403 patients presenting acutely with young (age $\leq 40$ year) CAD and admitted in the hospital during the period Jan 2005 - Dec 2009 was done.

The diagnosis of acute CAD was made on the basis of classical symptoms, diagnostic electrocardiogram (ECG) changes, cardiac injury enzymes and/or echocardiographic evidences [13]. Incomplete case records or those who had unexplained deaths were excluded from the study.

The case sheets were scrutinized for history pertaining to coronary risk factors, smoking and family history of young cardiovascular disorders (hypertension, diabetes, young CAD (in males $\leq 55$ years, females $\leq 65$ years) and cerebrovascular disease). Record analysis was also done for waist size, blood pressure recordings and positive history of hypertension, fasting and postprandial blood sugar and lipid profile (total cholesterol, high density lipoprotein cholester- 
Table 2. Coronary Risk Factor Profile of Patients With Metabolic Syndrome and CAD

\begin{tabular}{|c|c|c|c|c|}
\hline & $\begin{array}{c}\text { Total } \\
(n=66)\end{array}$ & $\begin{array}{c}\text { Male } \\
(n=53)\end{array}$ & $\begin{array}{l}\text { Female } \\
(n=13)\end{array}$ & P value \\
\hline Smoking & $47(71.1 \%)$ & $42(79.2 \%)$ & $5(38.5 \%)$ & $<0.025$ \\
\hline Family History & $26(39.4 \%)$ & $18(34.0 \%)$ & $8(61.5 \%)$ & NS \\
\hline $\begin{array}{l}\text { Mean number of components } \\
\text { of MS }\end{array}$ & $2.61 \pm 0.68$ & $2.57 \pm 0.67$ & $2.77 \pm 0.73$ & NS \\
\hline $\begin{array}{l}\text { Fasting plasma glucose } \geq 100 \text { or } \\
\text { previously diagnosed DM }\end{array}$ & $35(53.0 \%)$ & $27(50.9 \%)$ & $8(61.5 \%)$ & NS \\
\hline Hypertension & $36(54.5 \%)$ & $26(49.1 \%)$ & $10(76.9 \%)$ & NS \\
\hline $\begin{array}{l}\text { Reduced HDL cholesterol }(<40 \\
\mathrm{mg} / \mathrm{dL} \text { in males and }<50 \mathrm{mg} / \mathrm{dL} \\
\text { in females })\end{array}$ & $55(83.3 \%)$ & $43(81.1 \%)$ & $12(92.3 \%)$ & NS \\
\hline $\begin{array}{l}\text { Increased Triglycerides }(\geq 150 \\
\mathrm{mg} / \mathrm{dL})\end{array}$ & $49(74.2 \%)$ & $40(75.5 \%)$ & $9(69.2 \%)$ & NS \\
\hline Total cholesterol (mg/dL) & $179 \pm 54.5$ & $178.8 \pm 59.2$ & $178.7 \pm 29.8$ & NS \\
\hline LDL cholesterol (mg/dL) & $102.7 \pm 52.1$ & $103.8 \pm 55.7$ & $98.2 \pm 35.1$ & NS \\
\hline HDL cholesterol (mg/dL) & $34.2 \pm 8.9$ & $33.6 \pm 8.6$ & $37 \pm 9.97$ & NS \\
\hline Triglycerides (mg/dL) & $195 \pm 89.8$ & $197.6 \pm 94.9$ & $183.4 \pm 67.3$ & NS \\
\hline
\end{tabular}

NS- not significant.

ol (HDL-C), low density lipoprotein cholesterol (LDL-C), triglycerides). Note was also made of carotid intima media thickness (CIMT) as recorded. Smoking was defined as continuous use of cigarette or bidi (bidis are small hand-rolled cigarettes wrapped in a piece of local tobacco leaf). Dyslipidemia was considered as per NCEP-ATP III guidelines [14]. Hypertension was diagnosed according to JNC 7 criteria [15]. Diabetes mellitus was defined as per American Diabetes Association, 2004 criteria [16]. Prediabetes was defined as fasting blood sugar between 100 - $125 \mathrm{mg} / \mathrm{dl}$ (impaired fasting glucose) (IFG) and post prandial blood sugar between 140 - $199 \mathrm{mg} / \mathrm{dl}$ (impaired glucose tolerance) (IGT). Waist girth $\geq 90 \mathrm{~cm}$ in men and $\geq 80 \mathrm{~cm}$ in women was considered as abdominal obesity [17].

For the purpose of study, the criterion advocated by International Diabetes Federation (IDF) consensus 2005, which lays impetus on ethnic inheritance in diagnosis of obesity, was used for diagnosing patients with MS [17]. Thus, any patient presenting with abdominal obesity (defined by waist circumference $\geq 90 \mathrm{~cm}$ in males and $\geq 80 \mathrm{~cm}$ in $\mathrm{fe}$ males) plus two or more of the following risk factors was diagnosed with metabolic syndrome: 1) Blood pressure $\geq$ $130 / \geq 85 \mathrm{mmHg}$ or treatment of previously diagnosed hy- pertension; 2) Fasting blood glucose $\geq 100 \mathrm{mg} / \mathrm{dL}$ or previously diagnosed type 2 diabetes; 3 ) Triglyceride $\geq 150 \mathrm{mg} /$ $\mathrm{dL}$ or specific treatment for this lipid abnormality; 4) HDL cholesterol $<40 \mathrm{mg} / \mathrm{dL}$ in males and $<50 \mathrm{mg} / \mathrm{dL}$ in females or specific treatment for this lipid abnormality.

The intima media thickness (IMT) of the carotid artery was determined by a high resolution B mode USG System having an electronic linear, high frequency broadband transducer for superficial scanning with a mid frequency of 7.5 MHz. It was measured at several areas along the vessel wall including (1) the posterior aspect of the common carotid artery, (2) common carotid artery bifurcation, and (3) anterior wall of internal carotid artery. IMT measurements were quantified as the average of arterial wall thickness (excluding segments involved with plaque). Note was made of presence of any plaque. The data was then used to find the prevalence of derangement of various metabolic parameters in all patients and in those with MS.

Statistical analysis was done using SPSS v.17. Continuous variables were expressed as mean $\pm \mathrm{SD}$ and percentage was calculated for categorical variables. Comparison of continuous and categorical variables was done in male and female group using unpaired 2-tail t-test and chi-square test. 


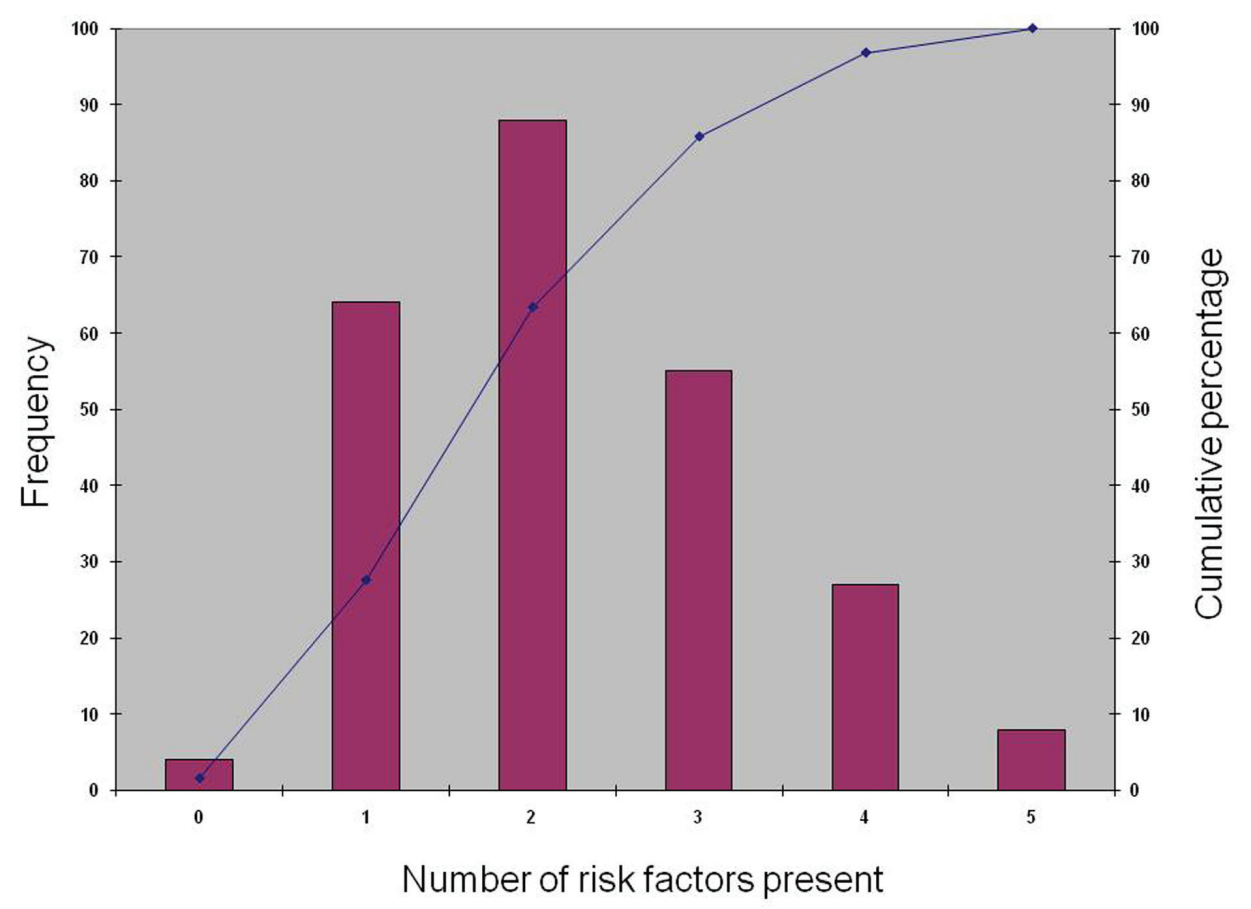

Figure 1. Cumulative frequency graph depicting the distribution of number of risk factors in patients with young CAD.

\section{Results}

Medical records of a total of 403 young patients with acute CAD were initially studied and after applying inclusion and exclusion criteria, 246 patients were selected for study. Out of 246 patients, $218(88.6 \%)$ were males and $28(11.4 \%)$ were females. Mean age at the time of admission was 36.3 \pm 4.1 years (range 23 to 40 years). The average age of male patients was $36.2 \pm 4.1$ years and average age of female patients was $37.5 \pm 3.5$ years. The coronary risk factor profile of young CAD patients is shown in Table 1 .

Overall, reduced HDL was the most common metabolic derangement present in patients with young CAD found in 171 patients $(69.5 \%)$, as compared to raised triglycerides levels in 103 patients $(41.9 \%)$, hypertension in 55 patients (22.4\%) and impaired fasting glucose and diabetes mellitus in 54 patients $(21.9 \%)$. In all young patients who had CAD, mean value of total cholesterol, LDL cholesterol, HDL cholesterol and triglycerides was $171 \pm 51.8 \mathrm{mg} / \mathrm{dL}, 102.5 \pm$ $45.8 \mathrm{mg} / \mathrm{dL}, 36.7 \pm 9.3 \mathrm{mg} / \mathrm{dL}$ and $156 \pm 85.7 \mathrm{mg} / \mathrm{dL}$ respectively. $187(75.6 \%)$ patients had history of smoking, 64 patients $(26.0 \%)$ had a positive family history of young cardiovascular disorders.

Metabolic syndrome was found in 66 patients $(26.8 \%)$. 13 females out of $28(46.4 \%)$ and 53 males out of 218 $(24.3 \%)$ met criteria for diagnosis of MS. The increased prevalence of MS in females was statistically significant compared to males $(\mathrm{P}<0.02)$. The coronary risk factor profile of young CAD with MS is shown in Table 2. Among
66 patients diagnosed with MS, low HDL was seen in 52 patients $(78.8 \%)$, raised triglycerides in 49 patients $(74.2 \%)$, hypertension in 36 patients $(54.5 \%)$ and dysglycemia in 35 patients $(53.0 \%)$. In patients who also had MS, the average value of total cholesterol was $179 \pm 54.5 \mathrm{mg} / \mathrm{dL}$, average value of LDL cholesterol was $102.7 \pm 52.1 \mathrm{mg} / \mathrm{dL}$, average value of HDL cholesterol was $34.2 \pm 8.9 \mathrm{mg} / \mathrm{dL}$ and average value of triglycerides was $195 \pm 89.8 \mathrm{mg} / \mathrm{dL}$. Among the 66 patients who had MS, 47 patients $(71.2 \%)$ had history of smoking. A positive family history of premature cardiovascular disorders was present in 26 patients (39.4\%).

Among patients with young CAD, prevalence of smoking was more in males compared to female patients $(\mathrm{P}<$ 0.005) whereas there was increased presence of hypertension and obesity in female patients compared to male patients $(\mathrm{P}<0.005)$. Out of total 246 patients with young CAD, 4 patients $(1.6 \%)$ had none of the 5 risk factors including central obesity, hypertension, dysglycemia, reduced HDL-C, and raised triglycerides. 64 patients $(26.0 \%)$ had 1 out of those factors, 88 patients $(35.8 \%)$ had 2 factors, 55 patients $(22.4 \%)$ had 3 factors and 27 patient $(11.0 \%)$ had 4 factors and 8 patients (3.2\%) had all 5 risk factors (Fig. 1).

Out of total 66 patients with young CAD who had MS, 33 patients $(50 \%)$ had 2 out of 4 factors by IDF consensus as listed above, 26 patients $(39.4 \%)$ had 3 factors and 7 patients $(10.6 \%)$ had all 4 factors above and over the obesity which is a pre-requisite for diagnosis of MS (Fig. 2). The mean number of components of MS in patients was $2.61 \pm 0.68$. The mean number of components of MS in males and females 


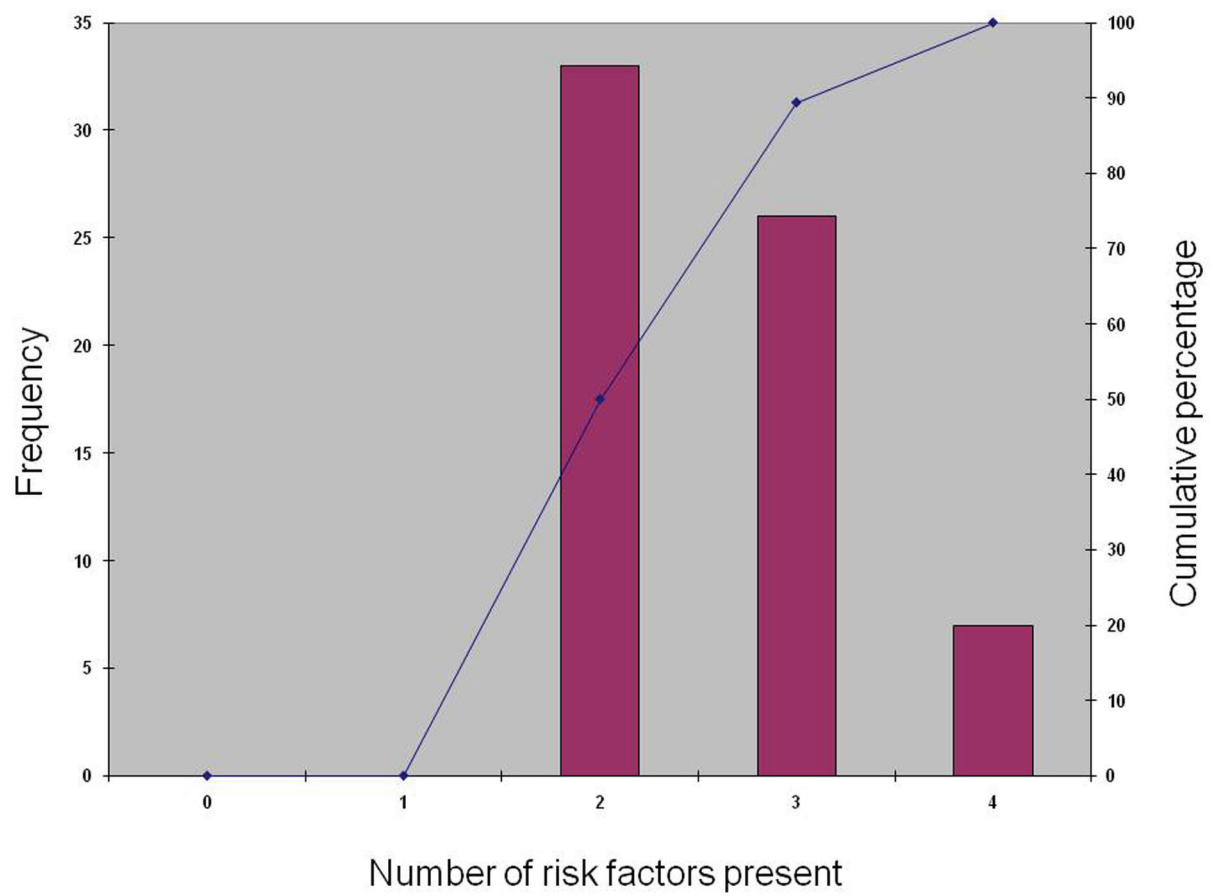

Figure 2. Cumulative frequency graph depicting the distribution of number of risk factors in young CAD patients with Metabolic Syndrome.

was $2.57 \pm 0.67$ and $2.77 \pm 0.73$ and the groups were not statistically significantly different with regards to the same.

The mean carotid intima media thickness (CIMT) measurement was $0.063 \pm 0.015 \mathrm{cms}$ in patients with young CAD with plaque present in $12.4 \%$ patients. The mean CIMT was $0.065 \pm 0.015$ in patients with MS with plaques in $15.6 \%$.

\section{Discussion}

Earlier studies using NECP ATP III criteria and IDF consensus criteria have shown prevalence of MS among Indian population to range from $18.3 \%$ to $41 \%$ [18-21]. However, this prevalence increases dramatically in patients with CAD and studies have shown prevalence of MS in patients with young/early onset CAD to range from $37 \%$ to $60 \%[12,22$, 23]. However, our study showed a prevalence of $26.8 \%$ in young Indian patients with CAD. This study also indicated that the prevalence of MS is more common in women than men (46.4\% versus $24.3 \%)$ in patients with young CAD and this increased prevalence in women is statistically significant with $\mathrm{P}<0.025$. This finding is of significant concern because studies have shown decreased survival in women with MS compared to women without MS [24]. Earlier studies have reported mixed results regarding predisposition of sex to development of MS. Some have indicated increased prevalence in females $[22,25,26]$; others have indicated increased prevalence in men $[19,20,27]$ while a study in US reported little difference in prevalence in general population between men and women [28].

The MS, which is characterized by risk factors like obesity, high blood pressure, impaired fasting glucose, raised triglycerides level and reduced levels of HDL cholesterol, has been considered to be a risk factor for CAD [8]. Studies have shown higher thrombolysis in myocardial infarction (TIMI) time frame indicating impaired blood flow in coronary arteries even in presence of angiographically normal coronary arteries in patients with MS as compared to patients without MS, which have been thought to play a crucial role in pathogenesis of disease [29].

In the present study smoking was found to be the most common single risk factor present in both young patients with CAD and MS. Earlier studies have also shown smoking to be the single most common risk factor present in patients with early onset CAD [30,31]. This study also indicated reduced HDL, increased waist circumference and increased TG levels to be the most common individual derangements in metabolic profile in young CAD patients and reduced HDL and increased TG in patients who also had MS. There was no significant difference in raised TG and reduced HDL levels in males and females, however, central obesity was significantly more in women as compared to men $(\mathrm{P}<$ 0.005). Earlier studies have also indicated reduced HDL and raised TG levels to be a significant metabolic derangement in Indian population $[19,32,33]$.

A major limitation of our study is that since it was a 
retrospective study, a large number of patient records had to be excluded from study due to absence of complete patient profile. Thus study sample may not be a true representative of the population of young CAD patients at large. Also, as there is difference in criteria for hypertension in JNC 7 and IDF, the hypertensive patients may be underrepresented in the study.

In conclusion, this study clearly indicates a high prevalence of MS in patients with young CAD and significantly higher prevalence in women than in men. Our study is important in fact that this is the first one to the best of our knowledge, which has studied the prevalence of MS in specifically young patients with CAD using IDF criteria. This study also underlies the importance of setting smoking and dyslipidemia as primary targets for effective prevention of $\mathrm{CAD}$ and $\mathrm{MS}$ in young Indians. Although, these modifiable factors do not completely explain the burden of CAD in Indian sub-continent, the identification of these factors is very important. Thus, screening of young healthy people and young CAD patients for MS may help find people at high risk for early development of CAD and can help health care workers to take more aggressive approach to more effective primary and secondary preventive measures and therapeutic measures.

\section{Author Contributions}

Amitesh Aggarwal and Sourabh Agarwal contributed equally to this work; including designing, performing research; analyzing the data; and writing the paper. Vishal Sharma was involved in performing research; analyzing the data; and writing the paper.

\section{Grant Support}

None.

\section{Financial Disclosures}

None.

\section{References}

1. Goyal A, Yusuf S. The burden of cardiovascular disease in the Indian subcontinent. Indian $\mathrm{J}$ Med Res. 2006;124(3):235-244.

2. Yusuf S, Reddy S, Ounpuu S, Anand S. Global burden of cardiovascular diseases: Part II: variations in cardiovascular disease by specific ethnic groups and geographic regions and prevention strategies. Circulation.
2001;104(23):2855-2864.

3. Anand SS, Yusuf S, Vuksan V, Devanesen S, Teo KK, Montague PA, Kelemen L, et al. Differences in risk factors, atherosclerosis and cardiovascular disease between ethnic groups in Canada: the study of health assessment and risk in ethnic groups (SHARE). Indian Heart J. 2000;52(7 Suppl):S35-43.

4. Joshi P, Islam S, Pais P, Reddy S, Dorairaj P, Kazmi K, Pandey MR, et al. Risk factors for early myocardial infarction in South Asians compared with individuals in other countries. JAMA. 2007;297(3):286-294.

5. Eapen D, Kalra GL, Merchant N, Arora A, Khan BV. Metabolic syndrome and cardiovascular disease in South Asians. Vasc Health Risk Manag. 2009;5:731-743.

6. Borch-Johnsen K. The metabolic syndrome in a global perspective. The public health impact--secondary publication. Dan Med Bull. 2007;54(2):157-159.

7. de Ferranti SD, Gauvreau K, Ludwig DS, Neufeld EJ, Newburger JW, Rifai N. Prevalence of the metabolic syndrome in American adolescents: findings from the Third National Health and Nutrition Examination Survey. Circulation. 2004;110(16):2494-2497.

8. Wannamethee SG, Shaper AG, Lennon L, Morris RW. Metabolic syndrome vs Framingham Risk Score for prediction of coronary heart disease, stroke, and type 2 diabetes mellitus. Arch Intern Med. 2005;165(22):26442650.

9. Amano T, Matsubara T, Uetani T, Nanki M, Marui N, Kato M, Arai K, et al. Impact of metabolic syndrome on tissue characteristics of angiographically mild to moderate coronary lesions integrated backscatter intravascular ultrasound study. J Am Coll Cardiol. 2007;49(11):11491156.

10. Lorenzo C, Williams K, Hunt KJ, Haffner SM. The National Cholesterol Education Program - Adult Treatment Panel III, International Diabetes Federation, and World Health Organization definitions of the metabolic syndrome as predictors of incident cardiovascular disease and diabetes. Diabetes Care. 2007;30(1):8-13.

11. Gami AS, Witt BJ, Howard DE, Erwin PJ, Gami LA, Somers VK, Montori VM. Metabolic syndrome and risk of incident cardiovascular events and death: a systematic review and meta-analysis of longitudinal studies. J Am Coll Cardiol. 2007;49(4):403-414.

12. Iribarren C, Go AS, Husson G, Sidney S, Fair JM, Quertermous T, Hlatky MA, et al. Metabolic syndrome and early-onset coronary artery disease: is the whole greater than its parts? J Am Coll Cardiol. 2006;48(9):18001807.

13. Luepker RV, Apple FS, Christenson RH, Crow RS, Fortmann SP, Goff D, Goldberg RJ, et al. Case definitions for acute coronary heart disease in epidemiology and clinical research studies: a statement from the AHA Council on Epidemiology and Prevention; AHA Statistics Com- 
mittee; World Heart Federation Council on Epidemiology and Prevention; the European Society of Cardiology Working Group on Epidemiology and Prevention; Centers for Disease Control and Prevention; and the National Heart, Lung, and Blood Institute. Circulation. 2003;108(20):2543-2549.

14. Brewer HB, Jr. New features of the National Cholesterol Education Program Adult Treatment Panel III lipid-lowering guidelines. Clin Cardiol. 2003;26(4 Suppl 3):III19-24.

15. Chobanian AV, Bakris GL, Black HR, Cushman WC, Green LA, Izzo JL, Jr., Jones DW, et al. The Seventh Report of the Joint National Committee on Prevention, Detection, Evaluation, and Treatment of High Blood Pressure: the JNC 7 report. JAMA. 2003;289(19):25602572.

16. American Diabetes Association. Clinical practice recommendations 2004. Diabetes Care 2004; 27:S141-2.

17. Alberti KG, Zimmet P, Shaw J. The metabolic syndrome--a new worldwide definition. Lancet. 2005;366(9491):1059-1062.

18. Deepa M, Farooq S, Datta M, Deepa R, Mohan V. Prevalence of metabolic syndrome using WHO, ATPIII and IDF definitions in Asian Indians: the Chennai Urban Rural Epidemiology Study (CURES-34). Diabetes Metab Res Rev. 2007;23(2):127-134.

19. Chow CK, Naidu S, Raju K, Raju R, Joshi R, Sullivan D, Celermajer DS, et al. Significant lipid, adiposity and metabolic abnormalities amongst 4535 Indians from a developing region of rural Andhra Pradesh. Atherosclerosis. 2008;196(2):943-952.

20. Sawant A, Mankeshwar R, Shah S, Raghavan R, Dhongde G, Raje H, D'Souza S, et al. Prevalence of metabolic syndrome in urban India. Cholesterol. 2011;2011:920983.

21. Ramachandran A, Snehalatha C, Satyavani K, Sivasankari S, Vijay V. Metabolic syndrome in urban Asian Indian adults--a population study using modified ATP III criteria. Diabetes Res Clin Pract. 2003;60(3):199-204.

22. Turhan H, Yasar AS, Basar N, Bicer A, Erbay AR, Yetkin E. High prevalence of metabolic syndrome among young women with premature coronary artery disease. Coron Artery Dis. 2005;16(1):37-40.

23. Ranjith N, Pegoraro RJ, Naidoo DP, Esterhuizen
TM. Metabolic syndrome in young Asian Indian patients with myocardial infarction. Cardiovasc J Afr. 2007;18(4):228-233.

24. Marroquin OC, Kip KE, Kelley DE, Johnson BD, Shaw LJ, Bairey Merz CN, Sharaf BL, et al. Metabolic syndrome modifies the cardiovascular risk associated with angiographic coronary artery disease in women: a report from the Women's Ischemia Syndrome Evaluation. Circulation. 2004;109(6):714-721.

25. Gorter PM, Olijhoek JK, van der Graaf Y, Algra A, Rabelink TJ, Visseren FL. Prevalence of the metabolic syndrome in patients with coronary heart disease, cerebrovascular disease, peripheral arterial disease or abdominal aortic aneurysm. Atherosclerosis. 2004;173(2):363-369.

26. Trevisan M, Liu J, Bahsas FB, Menotti A. Syndrome $\mathrm{X}$ and mortality: a population-based study. Risk Factor and Life Expectancy Research Group. Am J Epidemiol. 1998;148(10):958-966.

27. Isomaa B, Almgren P, Tuomi T, Forsen B, Lahti K, Nissen M, Taskinen MR, et al. Cardiovascular morbidity and mortality associated with the metabolic syndrome. Diabetes Care. 2001;24(4):683-689.

28. Ford ES, Giles WH, Dietz WH. Prevalence of the metabolic syndrome among US adults: findings from the third National Health and Nutrition Examination Survey. JAMA. 2002;287(3):356-359.

29. Turhan H, Erbay AR, Yasar AS, Bicer A, Sasmaz H, Yetkin E. Impaired coronary blood flow in patients with metabolic syndrome: documented by Thrombolysis in Myocardial Infarction (TIMI) frame count method. Am Heart J. 2004;148(5):789-794.

30. von Eyben FE, Bech J, Madsen JK, Efsen F. High prevalence of smoking in young patients with acute myocardial infarction. J R Soc Health. 1996;116(3):153-156.

31. Kanitz MG, Giovannucci SJ, Jones JS, Mott M. Myocardial infarction in young adults: risk factors and clinical features. J Emerg Med. 1996;14(2):139-145.

32. Sawant AM, Shetty D, Mankeshwar R, Ashavaid TF. Prevalence of dyslipidemia in young adult Indian population. J Assoc Physicians India. 2008;56:99-102.

33. Enas EA, Yusuf S, Mehta JL. Prevalence of coronary artery disease in Asian Indians. Am J Cardiol. 1992;70(9):945-949. 